\title{
DEGENERAÇÃO HEPATOLENTICULAR
}

\author{
A PROPósito DE 102 CASOS
}

HORACIO M. CANELAS *

Noo histórico da caracterização nosológica da degeneraçāo hepatolenticular (DHL) sobressaem os nomes de Westphal 103, Strümpell 85,86, Fleischer 31,32.33, Wilson 164 e Hall 43. No campo bioquimico destacam-se as pesquisas de Haurowitz 44, Lüthy 51, Uzman e Denny-Brown 91, Cumings 22, Holmberg e Laurell 45, Scheinberg e Gitlin 75, Bearn e Kunkel 7. Finalmente, cumpre mencionar Walshe 97.58, que introduziu um novo quelante no arsenal terapêutico, a penicilamina, cujos efeitos vieram desensombrar o prognóstico da moléstia.

Em nossa Clínica, a partir de 1946, foram estudados 102 pacientes com moléstia de Wilson. O diagnóstico baseou-se na comprovação de baixas conceritraçōes de ceruloplasmina e cobre séricos, de elevados indices de cuprúria, de quadro clínico compativel. Quanto ao sexo, 57 pertenciam ao masculine $(55,9 \%)$. Em relação à raça, 79 eram brancos $(77,5 \%)$, l8 pardos $(17,6 \%)$, 4 pretos $(3,9 \%)$ e 1 amarelo $(1,0 \%)$. Confrontando-se essas cifras com a freqüência geral em nosso hospital, verifica-se que é apenas aparente qualquer diferença de incidência em relação an sexo e à raça.

\section{QUADRO CLINICO}

Após acirradas polêmicas travadas no inicio do século entre a escola de Westphal, Strümpell e Alzheimer e os seguidores das idéias de Wilson, tornou-se evidente, com a revisāo da literatura feita em 1921 por Hall 43 que, nāo obstante a unidade nosográfica, a DHL apresenta duas variantes clínicas: a juvenil (forma de Wilson), em que as manifestações clinicas surgem entre os 7 e 16 anos, e a do adulto (pseudosclerose de Westphal-Strümpell), com inicio dos 17 aos 35 anos. $\mathrm{Na}$ primeira predominam a rigidez e as posturas anormais, e na segunda, o tremor e a disartria. Além dessas duas formas clínicas polares, podem ocorrer variantes com predomínio da distonia de torçāo, de movimentos coreatetóticos, de mioclonias ou mesmo de hemibalismos.

Em relaçāo à época de início da sintomatologia há na literatura registros de casos de instalação muito precoce, aos 4 (François e col.35) ou 13 meses (Liithy 51); Scheinberg e Sternlieb 78 observaram uma paciente que, aos 6 anos, começou a apresentar crises de grande mal; mas sinais extrapiramidais característicos só surgiram aos 11 anos. Outros casos têm começo tardio, após os 40 anos (Martin 54). Em nossos casos, a idade na instalação da sintomatologia variou entre 6 (forma hepática) e 9 (forma neurológica) e 49 anos. Houve nítida correlação com a forma clínica da moléstia, sendo significantes as diferenças entre as formas pseudosclerose e hepática e entre as formas de Westphal-Strümpell e de Wilson.

Trabalho do Departamento de Neurologia da Faculdade de Medicina da Universidade de Sảo Paulo: * Professor Titular. 
A lesão hepática, não obstante seu vulto, costuma ser assintomática. Contudo, em alguns casos, a doença se inicia por episódios de icterícia ou de outros sinais de disfunção hepática. Raramente as manifestações da hepatopatia precominam ou são exclusivas; nestes casos configura-se a "forma frusta" de Bramwell 15, ou "Wilson abdominal" de Kehrer 47, ou ainda a forma portal de van Bogaert e Willocx 11, a qual costuma caracterizar os estádios mais precoces da doença.

Nos pacientes não tratados adequadamente, a evolução da enfermidade é extremamente variável, porém a média é de 4 a 5 anos. A forma de Wilson apresenta curso mais rápido e é mais rebelde à terapêutica.

A sintomatologia inicial é bastante variável: os primeiros sintomas podem ser psíquicos, neurológicos ou digestivos.

Desordens emocionais e queda do rendimento escolar são manifestaçōes frequientes no início da enfermidade. A disartria é também um dos sintomas mais precoces; a princípio discreta, podendo simular gagueira ou um sotaque especial, progride para um borramento ou perda das consoantes; a fala torna-se lelita, podendo, entretanto, apresentar-se festinante; com o progredir da moléstia a disartria vai-se agravando, culminando em completa anartria.

A fácies costuma ser característica: de início retificação da rima oral, com repuxamento dos cantos da boca; com o evolver da moléstia, o paciente passa a exibir um riso estereotipado, com a boca entreaberta, a gengiva do maxilar superior exposta devido à retração do lábio na linha média.

O quadro neurológico é exclusivamente motor e dominado pela rigidez e por hipercinesias, ambas as manifestaçōes apresentando intensidade relativa de acordo com a variante clínica.

A rigidez começa geralmente por acometer um membro ou musculatura axial, evidenciando-se todo o seu cortejo semiológico: hipertonia plástica, exagero dos reflexos tônicos segmentares, sinal da roda denteada. Outros sinais da série parkinsoniana que costumam ocorrer na DHL são a seborréia da face e a sialorréia. Ulteriormente instalam-se posturas anormais dos membros, geralmente do tipo em flexão. O segmento cefálico também é habitualmente atingido, surgindo distúrbios da mastigação e deglutição; a protrusão da língua ou sua manutenção podem ficar prejudicadas. A marcha altera-se, tornando-se limitados 0.3 movimentos associados dos membros superiores, instalando-se dificuldade e depois incapacidade de correr, erguer-se de uma cadeira ou do solo, virar-se. Os movimentos tornam-se lentos e a diadococinesia é comprometida.

O tremor constitui dado semiótico do maior valor, embora não se encontre obrigatoriamente presente e não seja exclusivo da moléstia. Surge quando o paciente assume uma atitude com o membro. O ritmo se assemelha ao parkinconiano (4 a 8 por segundo), porém a amplitude é maior e atinge segmentos mais extensos. Geralmente se manifesta mais nitidamente nos membros superiores e bilateralmente. Quando o paciente estende os braços para a frente a movimentaçāo simula o adejo dos pássaros ("Flügelschlag", "wing-beating"). Intensifica-se durante o movimento e denota nitido caráter oposicionista. Ao realizar a prova index-nariz ou index-index, a amplitude aumenta no final do ato e o paciente geralmente não consegue manter o dedo imóvel no alvo determinado. A cabeça e o tronco podem ser acometidos pela hipercinesia. A emoção agrava o tremor e o sono o faz cessar.

Raras vezes a hipercinesia assume o tipo coréico ou coreatetótico. As formas distônicas, contudo, sāo mais encontradiças. A face e a lingua por vezes apresentam contrações espasmódicas quando o doente tenta falar. Um de 
nossos pacientes apresentava mioclonias arrítmicas da lingua e do véu; em outro havia mioclonias rítmicas da lingua.

No estádio final o paciente pode apresentar crises tônicas de descerebração; mais freqüentemente, porém, o paciente apresenta atitudes distônicas e contraturas das extremidades, do tipo em flexão.

A ocorrência de sinais piramidais geralmente não é mencionada na literatura mais recente. Wilson 104, porém, afirma que a zona lenticular amolecida pode invadir a cápsula interna, resultando sintomas corticospinais. Sinais de acometimento desse sistema foram registrados em 21 de 110 casos arrolados por Lüthy 51 e em apenas $4 \%$ de nossos casos. Sinais cerebelares, ocorreram em $10 \%$. Os nervos cranianos de regra são poupados, porém a convergência pode estar comprometida. Crises epilépticas têm sido observadas e revestem tanto o tipo generalizado, como focal, ou de ausência; convulsões ocorreram em $8 \%$ de nossos casos, geralmente na fase tardia.

Sintomas psiquicos constituiram a manifestação inicial em 10 a $25 \%$ da grande casuística de Scheinberg e Sternlieb 78 , que os atribuem tanto à reação a uma doença de tal gravidade, como aos efeitos tóxicos do cobre nos centros intelectuais e integradores do cérebro. A natureza desses sintomas é extremamente variável. Já referimos a queda do aproveitamento escolar como sinal precoce; podem seguir-se apatia, inércia, diminuição da memória e falta de concentração. As alteraçōes afetivas são comuns: as crianças tornam-se emotivas, irrequietas, irritáveis, agressivas. A expressão vaga e tola devida à fácies wilsoniana pode, porém, sugerir uma deficiência mental inexistente. Nas formas tardias podem configurar-se verdadeiras psicoses.

Manifestações sistêmicas - Afora os casos de forma portal, em geral a semiologia do fígado nada revela de anormal. É muito frequiente que as provas funcionais resultem normais, mesmo em casos nos quais a biópsia hepática já revela cirrose. Entretanto, a ultra-sonografia abdominal revela precocemente as alterações hepáticas (Cançado e col.i7). O baço é mais freqüentemente palpável que o figado 54 . Em algumas eventualidades a suspeita diagnóstica é despertada pela verificação de trombocitopenia ou pelo aparecimento de manifestaçōes hemorrágicas.

Dos sinais extraneurológicos o mais importante é o anel de Kayser-Fleischer. Consiste em um halo castanho-esverdeado situado na superfície interna do limbo corneano. De regra bilateral, pode ser incompleto ou de largura variável. De estructura delicada, como uma névoa, pode deixar de ser evidenciado se a luz da lanterna incidir perpendicularmente. Excepcionalmente, o anel só é visível à lâmpada de fenda. Segundo Cumings 23 , em crianças com menos de 8 anos de idade $o$ anel de Kayser-Fleischer $e$ as manifestações neurológicas geralmente estão ausentes. $\operatorname{Em~} 3$ de nossos pacientes o anel não foi pesquisado, tendo o diagnóstico sido feito pelo exame necroscópico. Em 91 casos estava presente. Dos 8 pacientes em que estava ausente, 5 eram assintomáticos e 3 tinham menos de 10 anos de idade. Assinale-se que o anel foi observado à lâmpada de fenda na irmã de um de nossos pacientes, a qual tinha 19 anos nessa ocasião, só vindo a apresentar sintomatologia neurológica 9 anos depois. $O$ anel resulta da deposição de grânulos de cobre na membrana de Descemet, como demonstra 0 estudo histoquimico 2,46. Com o tratamento pela penicilamina 0 anel pode reduzir-se ou mesmo desaparecer. O depósito de cobre no cristalino pode condicionar o aparecimento da chamada catarata em girassol.

Manchas cutâneas de coloraçăo marrom já haviam sido assinaladas por Fleischer 33 em seu primeiro caso e sua frequência deve ser maior que a mencionada na literatura 101. As áreas de hiperpigmentação cutânea têm variada localização, mas são mais frequientes nas faces anteriores da metade inferior das pernas. Ao contrário do que seria de supor, o fato năo se deve a acúmulo 
de cobre mas sim a aumento do pigmento melânico na camada basal da epiderme, talvez relacionado à disfunção hepática 48 ; não se esqueçam, contudo, as relações entre melanina e tirosinase, uma oxidase contendo cobre 30.

Lesões ósseas, de regra sob a forma de cistos nos ossos longos 54, têm sido encontradas na DHL; fraturas espontâneas podem levar à descoberta de alterações generalizadas do esqueleto, que podem preceder a instalação do quadro neurológico. $O$ exame radiológico pode demonstrar variadas alterações ostearticulares $13,17,29,56,70,101,102$.

Em nossa série predominaram os casos em que a moléstia se instalou com manifestaçōes exclusivamente neurológicas. Destaque-se a presença de ictericia em $29,6 \%$ dos casos e de manifestaçóes ostearticulares em $32,1 \%$ (contudo, a avaliação clinica, radiológica e cintilográfica das manifestaçōes articulares, realizada en 31 pacientes, revelou indices bem mais elevados 17 ).

\section{DIAGNÓSTICO ILABORATORIAL}

A dosagem de ceruloplasmina constitui elemento fundamental para o diagnóstico e pode ser realizada por métodos imunológicos ou por ensaios da atividade enzimática. O limite inferior da normalidade situa-se ao redor de $25 \mathrm{mg} / \mathrm{dl}$ de sangue. Os pacientes com DHL geralmente apresentam valores abaixo de $5 \mathrm{mg} / \mathrm{dl}$ e os heterozigotos, em torno de $15 \mathrm{mg} / \mathrm{dl}$.

A dosagem de cobre tem também grande interesse, não só para o diagnóstico, como para o controle do tratamento. O limite inferior da normalidade para o conteúdo de cobre total do sangue está em redor de $90 \mu \mathrm{g} / \mathrm{dl}$. Na DHL os valores são consideravelmente menores, podendo encontrar-se cifras abaixo de $40 \mu \mathrm{g}$. Essa queda é devida ao fato de que, segundo Holmberg e Laurell 45, $96 \%$ do cobre total estão incorporados na molécula da ceruloplasmina. O cobre livre, ligado à albumina, está elevado na doença 22 .

Na urina encontram-se valores de cobre ultrapassando o limite superior da normalidade. $O$ uso de penicilamina provoca, nos primeiros dias de tratamento, acentuada elevação da excreção urinária, que atinge valores de $5000 \mu \mathrm{g} / 24 \mathrm{~h}$ ou mais; este fato pode mesmo ser utilizado como teste diagnóstico.

Tem grande importância diagnóstica a determinação do cobre no fígado, em material colhido por biópsia. O limite superior da normalidade varia entre 10 (Scheinberg e Sternlieb 77) e $20 \mathrm{mg} / 100 \mathrm{~g}$ de material seco (Cumings 22). $\mathrm{O}$ estudo histológico geralmente demonstra a presença de cirrose pós-necrótica e o exame histoquímico revela acúmulo do metal, em maior quantidade nas células hepáticas que nas células estreladas 2 .

Nos rins a função tubular mostra-se comprometida, talvez em decorrência de uma ação tóxica do cobre. Tal fato explica o eventual aparecimento de glicosúria e o aumento da excreção de fosfatos e cálcio (que pode induzir osteoporose e fraturas patológicas) e ácido úrico (e consequientemente hipouricemia). Enquanto as concentraçốes sangüíneas de aminoácidos são baixas ou normais, as urinárias estão elevadas, configurando uma verdadeira aminoacidúria renal. As provas de função renal, de resto, costumam ser normais; as alteraçōes, quando existem, são discretas.

O exame eletrencefalográfico revelou-se normal em cerca de três quartos de nossos casos; nos demais, mostrou a existência de atividade irritativa, de desorganização do traçado ou de sofrimento cerebral. Em nossos pacientes a tomografia axial computadorizada tem confirmado os dados da literatura, revelando atrofias córtico-subcorticais, dilatação ventricular e/ou lesões hipoatenuantes do núcleo lenticular. 


\section{DIAGNóSTICO PRECOCE DOS FAMILIARES}

Tratando-se de doença transmitida por gene autossômico recessivo, mais de um membro da mesma familia pode ser acometido. Por vezes se encontra uma criança que apresenta icterícia, cirrose e/ou crises de anemia hemolitica, e ten um irmão mais velho com DHL. O exame dessa criança pode fornecer dados pouco elucidativos, pois abaixo de 8 anos de idade, como vimos, 0 anel de Kayser-Fleischer e os sinais neurológicos geralmente estão ausentes.

Uma em cada 200 pessoas da população em geral é heterozigota para DHL e $10 \%$ dos heterozigotos têm ceruloplasmina baixa. Logo, 1 entre 2000 pessoas receberia o diagnóstico de DHL se se tomasse por base apenas a hipoceruloplasminemia 84. No entanto, a frequiência da moléstia é de 3:100000 (Scheinberg c Sternlieb 78), o que significa que 94 heterozigotos seriam desnecessariamente tratados, com todos os riscos da terapêutica, para cada genuino paciente assin. tomático.

Sternlieb e Scheinherg 84 verificaram que a concentração média de cobre no fígado (por $100 \mathrm{~g}$, peso seco) era nos heterozigotos de $11,7 \mathrm{mg}$ (normais: 3,15 ), enquanto os homozigotos tinham médias de 58,83 quando sintomáticos e de 98,35 se assintomáticos. Trata-se de achado surpreendente, que os autores interpretam assim: possivelmente a lesão do SNC só se estabelece após ter sido vencida a capacidade-tampão do fígado em fixar cobre, que, liberado na circulação, penetra no encéfalo.

A medida de incorporação de $64 \mathrm{Cu}$ na ceruloplasmina é dada pela relação entre as concentrações de radiocobre no soro às $48 \mathrm{~h}$ e 1 ou $2 \mathrm{~h}$ após a ingestão de $2 \mathrm{mg}$ de cobre com atividade de 0,5 a $2,0 \mathrm{mC}$ (Sass-Kortsak e col.71, Sternlieb e col.83). Em 19 controles normais, 19 pais de pacientes com DHL e 7 destes doentes, as médias geométricas dessa relaçăo foram, respectivamente, de 1,372, 0,510 e 0,171 ; Sternlieb e col.82 concluem que essa relaçāo constitui um método adequado para distinguir os portadores heterozigotos do gene da DHL, dos individuos homozigotos para seu alelo normal.

Osborn e Walshe 65 verificaram que um paciente com DHL concentrava no figado menos de $17 \%$ do cobre injetado $(7,5$ a $12,0 \mu \mathrm{C})$ enquanto os pais heterozigotos concentravam de 40 a $59 \%$ e os irmáos, presumivelmente homozigotos normais, captavam mais de $70 \%$.

Outro método consiste em medir a captação de cobre radioativo no fígado e na coxa, obtendo assim lum indice que normalmente é de 2,0 enquanto na DHL ele cai a 0,8 ; por outro lado, o acúmulo de cobre no fígado é mais rápido na forma hepática que na neurológica tardia 66 . A liberação de radiocobre hepático, que se completa em uma semana, é retardada e incompleta nos heterozigotos e muito diminuida nos homozigotos 62 .

Năo havendo insuficiência hepatolenticular o "turnover" corporal do radiocobre pode ser usado para identificar o defeito genético: a meia-vida média normal é de 27 dias, passando nos heterozigotos a 111 dias 63 .

Outros estudos mostraram que a concentração de radiocobre nas fezes durante 10 a 14 dias após a administração intravenosa era de 24 a $40 \%$ da dose nos normais, de 7,8 a $23,8 \%$ nos heterozigotos e de 3,7 a $13,2 \%$ nos homozigotos; esta redução nas fezes é provavelmente conseqüente à diminuição da excreção biliar de cobre 64 .

\section{ANATOMIA PATOLÓGICA}

A idéia original de Wilson, de que as lesões se restringem aos gânglios da base e ao fígado, não resistiu aos resultados dos estudos subsequientes 54 . Embora 
o putâmen seja realmente a estrutura mais comprometida, seguido pelo globo pálido e núcleo caudado, outras formações (núcleo subtalâmico, tálamo, núcleo rubro, substância negra, núcleo denteado) e o próprio córtex cerebral podem ser afetados 42. No SNC os niveis de cobre são particularmente elevados no córtex, gânglios da base, substância negra, núcleo rubro e córtex cerebelar 23,41; as cifras costumam ser 5 ou mais vezes superiores às normais. Em pacientes que faleceram em conseqüência da cirrose hepática e sem manifestaçōes neurológicas têm sido observadas lesöes degenerativas praticamente limitadas ao putâmen $\mathbf{5 4}$.

Importa frisar que, nos casos de início tardio, referidos geralmente como forma pseudosclerótica, não se encontram padrões histológicos caracteristicos que possam individualizá-la e distinguíla da forma de Wilson. Existem várias combinaçōes de lesões ativas e indolentes, e vários graus de comprometimento entre os locais preferenciais de lesão, de maneira que não se pode clasificar a DHL, do ponto de vista patológico, em formas polares.

Os núcleos lenticulares mostram atrofia simétrica e coloração amarela ou avermelhada; a consistência é mais suave que a normal, principalmente no putâmen, onde se podem ver fissuras e depressōes, dando à estrutura um aspecto de tecido "roído por vermes" ("vermoulu"); ou então o putâmen pode apresentar desintegração maciça, substituido por uma grande cavidade cística, principalmente em sua porção lateral; em alguns casos, a zona necrótica pode atingir a cápsula externa e o claustro. O globo pálido, geralmente pequeno e descorado, raramente mostra desintegração grosseira; o núcleo caudado é o menos comprometido, mas sua superfície ventricular está achatada.

As alteraçōes microscópicas são extremamente variáveis em relação ao tipo e distribuição, mas algumas feições são tão características que a doença de Wilson permanece como entidade histológica bem definida. O processo é puramente degenerativo $e$ atinge as estruturas de suporte, os mecanismos de reparação e todos os constituintes parenquimatosos do tecido. Por todo o cérebro encontra-se aumento difuso de astrócitos de aspecto normal. Astrócitos gigantes de Alzheimer são vistos em várias regiōes, porém se encontram em maior quantidade dentro ou na periferia das áreas com degeneração parenquimatosa. Estas células são classificadas em tipos I e II, sendo o tipo II muito mais comum. As células de Opalski 61 são encontradas principalmente na substância cinzenta do córtex e dos gânglios da base, em associação com a glia de Alzheimer e também geralmente próximo aos focos de degeneração.

O fígado apresenta tamanho menor que o normal; é descolorido; sua superfície mostra nódulos de tamanhos variáveis. Microscopicamente, o processo cirrótico é do tipo pós-necrótico, com variaçōes regionais na morfologia histológica. Uzman 90 demonstrou, por método histoquímico com ácido rubeânico, que as células de Kupffer não contêm cobre; este se deposita no hepatócito e há pouco acúmulo de cobre no tecido conjuntivo trabecular. A microscopia eletrônica evidenciou que o lisossomo da célula hepática era a estrutura que acumulava o cobre 81 . O baço é geralmente de volume aumentado em conseqüência de fibrose e congestão. Nos ossos observa-se osteoporose difusa ou focal e fragmentaçăo do osso na superfície articular; por vezes se caracteriza a osteomalacia. Foram descritas lesōes no coração 3,14. Nos rins não foram encontradas alteraçōes estruturais consistentes.

\section{RELACÓES ENTRE A DHL E OUTRAS MOLÉSTIAS HEPATOCEREBRAIS}

Segundo Adams e Foley 1 , a astrocitose protoplasmática difusa, com alteraçōes relativamente discretas dos elementos neuronais do cérebro, constitui uma característica não só da DHL como de hepatopatias graves de diversas etiologias, com sintomatologia neurológica durante vários dias antes do óbito; esses autores não encontraram células de Opalski nestes casos. porém as células 
tipos I e Il de Alzheimer eram muito freqüentes. Estes resultados foram formalmente contraditados por Baker 4 , e Lumsden 49 ressalta que se trata de resposta de tipo agudo e que, por analogia com outros processos neuropatológicos, a astrocitose protoplasmática deveria evolver para o tipo fibroso em prazo relativamente curto. Note-se, porém, que o grupo de Adams, em trabalho ulterior 92, apresenta o resultado do estudo de sobreviventes de coma hepático apresentando sintomatologia neurológica durante longos períodos, de até 10 anos; foram encontradas células de Opalski nestes casos. Por outro lado, em macacos com encefalopatia experimental por amônia foi observada proliferação de astrócitos protoplasmáticos, sendo encontradas células do tipo II de Alzheimer e não as do tipo I; elementos semelhantes às células de Opalski também foram assinalados 21. Experiências de Mossakowski e col.60 em culturas de astrócitos demonstraram que as células de Opalski sāo obtidas seja por intermédio de adição de soro de pacientes com DHL ou coma hepático, seja após administração de ions exógenos de cobre ou amônia.

Por outro lado, a existência de doenças hepáticas que simulam a DHL, tanto nas manifestações sistêmicas e neurológicas, como em aspectos laboratoriais, suscita, eventualmente, grandes dificuldades diagnósticas 93. Entre essas hepatopatias destaca-se a cirrose biliar primária que, em sua fase de insuficiência hepatocelular, pode acompanhar-se de distonias, atetose e coreatetose, e mesmo, por vezes, de anel pigmentado na córnea 34,39 . Entretanto, a sintomatologia inicia-se em faixa etária bem mais avançada do que sói ocorrer na DHL. Do ponto de vista laboratorial, a presença de hipercuprúria e de altas concentraçōes de cobre no fígado constitui dado desconcertante, porém a distinção é feita pela existência de altos níveis de ceruloplasmina e cobre sérico.

A dificuldade do diagnóstico diferencial aumenta quando a DHL se inicia como hepatopatia, não sendo infreqüente sua manifestação como hepatite crônica ativa 79 .

Cumpre ressaltar que as eventualidades acima referidas são extraordinariamente raras e que o caráter genético da $\mathrm{DHL}$ pode auxiliar no diagnóstico diferencial.

\section{ETIOPATOGENIA}

O caráter familial da moléstia já havia sido reconhecido desde as primeiras descrições; 8 dos 12 casos relatados em 1912 por Wilson 104 pertenciam a três famílias. Após o descobrimento de sua natureza metabólica, observou-se que, quando a DHL é diagnosticada, o distúrbio bioquímico pode ser encontrado em pais, filhos e irmãos assintomáticos. Admite-se que a herança seja autossômica recessiva 6 .

O organismo metaboliza o cobre a partir dos alimentos, nos quais o metal se encontra ligado principalmente às proteínas e aos aminoácidos. Pequtenas quantidades săo eliminadas pela urina, mas a bile é a via de excreção mais importante 64 .

O cobre absorvido do trato intestinal liga-se labilmente com a albumina plasmática, que assim o transporta até o fígado e a outros tecidos. No fígado desfaz-se a ligação Cu-albumina e o cobre passa a ser incorporado na metalotioneína 67 e daí transferido a partículas celulares para gerar cuproproteinas, como a ceruloplasmina, a citocromo-oxidase e a superoxidodismutase. A citocromo-oxidase é importante como enzima final do metabolismo oxidativo e a superoxidodismutase é a enzima protetora das células nas açōes tóxicas dos radicais superóxido 102 .

A ceruloplasmina é uma globulina $\alpha_{2}$, contendo $0,3 \%$ de cobre e constituida por 6 átomos de cobre 78 normalmente carreia $96 \%$ do cobre sangüíneo (Holmberg e Laurell 45). Estudos com radioisótopos mostraram que a cerilo- 
plasmina humana, en presença de neuraminidase (que a degrada, liberando ácido siálico), desaparece da circulaçăo do coelho en alguns minutos, encuanto a ceruloplasmina do animal tem vida média de 56 horas; se o resíduo galactosidico for removido pela glactosidase, a vida média da ceruloplasmina retorna aio normal. Estes estudos 58 permitiram formular a hipótese de que, na DHL, laveria um defeito genético no sistema enzimático que catalisa a transferência de ácido siálico para a molécula de ceruloplasnina. Por outro lado, parece provável que esta funcione como proteina de armazenamento. A degradação da ceruloplasmina se faz no lepatócito após a remoçāo de dois dos residuos terminais de ácido siálico; a clivagem ocorre provavelmente nos lisossomos.

Mediante métodos imunológicos, Carrico e col.19 demonstraram a existência de apoceruloplasmina no soro humano. Sua concentraçāo normal é da orden de $4,8 \mathrm{mg} / \mathrm{dl}$ caindo na DHL para 1,4 ; essa redução é, entretanto, inferior à da holeceruloplasmina, pois o quociente holo/apoceruloplasmina, que normalmente é de 11,3, na DHL passa a 1,7 (Matsuda e Holtzman 55).

Por meio de cromatografia e eletroforese foran separadas duas espécies de ceriiloplasmina ( $\mathrm{l}$ ou $\mathrm{C}-\mathrm{C}$ e $\mathrm{Il}$ ou $\mathrm{C}$-d), provavelmente relacionadas ao polimorfismo genético de isozimas. Seu significado na patogenia da DHL, entretanto, é obscuro, pois o conteudo de cobre, aminoácidos e carboidratos, ben como a atividade enzimática e as características espectrais, sāo idênticas em ambas as frações cromatográficas 75 .

$\dot{E}$ indiscutivel o fato de que somente na DHL e na carência de cobre se observa lentidão na sintese de ceruloplasmina 75. Portanto, era lógico que a primeira teoria etiopatogênica inculpasse os distúrbios na sintese de ceruloplasmina como determinantes da DHL. Algumas observaçōes, entretanto, parecem contraditar essa teoria: a) nāo há relaçāo obrigatória entre grau de redução de síntese de ceruloplasmina e quantidade de cobre depositada nos tecidos; b) os heterozigotos podem possuir concentraçōes muito baixas de ceruloplasnina e nunca desenvolvem sintomatologia clinica.

En um dos rarissimos casos de DHL com niveis normais de ceruloplasmina foi verificado retardo na integração do cobre radioativo na molécula de ceruloplasmina, aventando-se a hipótese de que talvez a sua estrutura química fosse anormal 71. Tais fatos poderiam explicar porque os heterozigotos permanecen sadios apesar da baixa concentração de ceruloplasmina, pois parte desta seria qualitativamente normal, enquanto o doente com o mesmo valor quantitativo pode possuir uma variante anormal 72 .

Após ser absorvido ao nivel intestinal, parte do cobre é depositada no figado para ser incorporada, em minutos ou horas, na cuproproteina hepática isolada em 1938 por Mann e Keilin 52, a qual apresenta aproximadamente a mesma composiçāo em aminoácidos mas contém maior concentração de cobre nos pacientes com DHL que nos normais 59 . No doente com DHL parece não se efetuar a transferência de cobre da cuproproteina hepática para a ceruloplasmina, provavelmente em razão de um defeito genético na sintese desta última. Outra parte do cobre proveniente do trato intestinal se liga à lactose-6-desidrogenase, à citocromo-oxidase, à tirosinase e a outras cuproproteinas.

Adiminstrando-se $64 \mathrm{Cu}$ a coelhos, verifica-se que a atividade do cobre na ceruloplasmina se aproxima, porém não excede, a da hepatocupreína durante horas. Em individuos normais o radiocobre administrado logo aparece no sangue como cobre livre em alta concentração, que rapidamente cai, para depois reaparecer como integrante da molécula de ceruloplasmina. Sendo de 132.000 seu peso molecular 76 , pouco cobre se difunde através das membranas capilares para os compartimentos inter ou intracelular. Já na DHL uma parte do cobre hepático alcança o plasma em tempo, mas, năo estando incorporado na ceruloplasmina, é livre para se difundir através das membranas capilares; grande parte é excretada, mas o restante penetra nas células em maior quantidade 
que normalmente 72 , depositando-se em quase todos os tecidos do organismo, particularmente no figado, cérebro e córnea.

O cobre excretado nas fezes provém: a) do cobre da dieta que não foi absorvido; b) do cobre que passou pelo hepatócito e se ligou a duas frações protéicas especificas da bile, com pesos moleculares de aproximadamente 4.000 5.000 e 8.000 (Fronmer 38); c) de secreções cono saliva e sucos gástricos, pancreático e jejunal; (d) do catabolismo fisiológico da ceruloplasmina. Na DHL a excreçāo do cobre pela bile está reduzida à metade 37 , o que induziu à idéia errônea de um aumento da absorçăo intestinal desse metal 105. $O$ balanço metabólico do metal é positivo, pois o aumento da excreção urinária é insuficiente para compensar a diminuição da excreção fecal (O'Reilly e col.64). Segundo estes autores, é admissivel que a anormalidade da metabolização hepática e a reduçāo da excreção biliar do cobre estejam estreitamente relacionadas com o alelo e o gene anormal na DHL.

Discute-se se a lesão celular é determinada por um efeito tóxico do cobre. Tal suposição é apoiada pelos resultados obtidos em ratos por Palladini e col.68 que, administrando intraperitonealmente azida sódica e um sal uréico de cobre, produziram lesões encefálicas muito semelhantes às observadas na DHL. Dados experimentais e histopatológicos, em animais $5,50,95$ e no homem 95 , sugerem uma interferência do acúmulo de metal na atividade enzimática intracelular, particularmente das mitocôndrias neuronais e dos lisossomos hepatociticos. O cobre inibe a enzina adenosina-trifosfatase da membrana microssômica, deterninando bloqueio no transporte iônico 102.

\section{TRATAMENTO}

Até lá poucos anos, tentara-se o tratamento da DHL por meio de uma resina permutadora de ions (etilenodiaminotetracetato dissódico de cálcio, Versene) ou de um quelante (2,3-dimercaptopropanol, BAL) e infusão de ceruloplasmina pura 9,74 , com resultados nulos ou mediocres.

Atualmente, o tratamento é feito com a D-penicilamina, adjuvada com $o$ emprego de sulfeto de potássio visando a diminuir a quantidade de cobre absorvível; embora alguns 12,36,87 neguem a eficácia do $\mathrm{K}_{2} \mathrm{~S}$, outros a aceitam 10,69,73. Recomenda-se a adoção de dieta vegetal, que reduz a positividade do balanço metabólico de cobre 18. E importante frisar que nenhuma dieta livremente escolhida possui tão pouco cobre que evite o aparecimento da moléstia em um homozigoto: a ingestão de $50 \mathrm{~g}$ por dia é suficiente para encharcar os tecidos desses pacientes 84 .

A penicilamina, ou ácido- $\alpha$-amino- $\beta$-mercapto-isovalérico, ou ainda $\beta, \beta$-dimetilcisteina, foi descoberta en 1953 por Walshe 96 na urina de individuos submetidos a tratamento com penicilina, atingindo maiores niveis em pacientes com lesão hepática. É um produto de hidrólise da penicilina que, por possuir um carbônio assimétrico, se apresenta sob formas isoméricas; a configuraçăo dextrógira é a preferida, por ser menos tóxica 28. Em 1956 foi introduzida no tratamento da DHL por Walshe 97,98. A administração oral desse agente determina elevação do cobre plasmático e intenso aumento da cuprurese.

Apenas pequena percentagem do cobre presente em individuos normais ou com DHL consegue franquear uma membrana semipermeável in vitro. Após incubação com penicilamina $0,02 \mathrm{M}$ o cobre é mobilizado de tal forma que 29 a $37 \%$ do cobre sérico dos normais e 77 a $87 \%$ dos pacientes com DHL franqueimam a membrana. É provável que um átomo de cobre seja incorporado por duas moléculas de penicilamina 57.

Atualmente, devido à possibilidade de reações colaterais, recomenda-se iniciar com 250mg por dia, aumentanđo-se igual dose cada 4 dias, até atingir 
$1.00 \mathrm{mg}$; insistir nesta dose durante três meses e só aumentá-la se se tiver mostrado ineficaz. O medicamento deve ser ministrado meia hora antes das refeições a fim de evitar a sua combinação com o cobre dos alimentos. A longo prazo observa-se eventualmente certa redução da eficácia terapêutica, o que pode obrigar à elevação da dose 89 .

Os resultados geralmente começam a manifestar-se depois de um ou dois meses de tratámento, mas por vezes as melhoras já se evidenciam após duas semanas. Tal fato decorre da reorganização dos grupamentos sulfidrilas de enzimas subcelulares necessárias para o metabolismo oxidativo, porém persiste a elevaçāo dos níveis de cobre tecidual 53. Os resultados variam de doente para doente, mas geralmente são melhores nas formas tardias, tipo pseudosclerose, ponto em que a nossa experiência concorda integralmente com a de Denny-Brown 25. De acordo com a evoluçăo clínica e com os níveis de cuprurese, pode-se passar a doses de manutenção da ordem de $500 \mathrm{mg}$ diários. A terapêutica não deve ser interrompida durante a vida toda do paciente, observando-se sempre recaidas quando tal acontece.

O efeito da medicação é ratificado, em alguns casos, pela diminuição ou desaparecimento do anel de Kayser-Fleischer. Há também aumento da captaçāo hepática de radiocobre após tratamento prolongado 40. Em 2 pacientes de Cumings 24 que faleceram em coma hepático após vários anos de tratamento com BAL e penicilamina, as concentrações de cobre no fígado e cérebro se haviam provavelmente reduzido, pois se situavam quase dentro da faixa normal. Isto geralmente ocorre após 5 anos de tratamento 53 .

Até 19616 de nossos pacientes foram tratados com BAL e 2 com resina permutadora de ions, sempre sem resultado favorável. A partir de 1962 passamos a empregar D-penicilamina, estando atualmente com 84 pacientes tratados. Os melhores resultados foram observados nos casos de pseudosclerose de Westphal-Strümpell, não obstante a maior duração média da moléstia neste grupo. Em nossos pacientes, o tratamento com penicilamina provocou nítida elevação dos valores médios de ceruloplasmina e cobre sérico, bem como da cuprúria. A modificação, entretanto, não se revelou estatisticamente significante, em vista da grande dispersão dos dados.

Os efeitos colaterais são infreqüentes e geralmente caracterizados pelas reaçóes de hipersensibilidade e alterações da série branca e/ou plaquetínea. Têm sido descritos casos de nefrose. A penicilamina provoca espoliação de piridoxina, que deve ser administrada na dose de $50 \mathrm{mg}$ ao dia. O tratamento dos efeitos colaterais consistiu na suspensão temporária da droga e no uso de prednisona (30 a $60 \mathrm{mg} / \mathrm{dia})$. Somente em um paciente não foi possível reintroduzir a penicilamina. Em nenhum dos 13 casos estudados foi verificada a presença de células LE ou de fator antinúcleo.

Sunderman e col.88 obtiveram bons resultados clinicos e bioquímicos em um paciente tratado com dietilditiocarbamato de sódio, um reagente utilizado na dosagem de cobre em materiais biológicos.

Em casos de reações tóxicas à D-penicilamina tem sido utilizado, com bons resultados clínico-laboratoriais, outro quelante, o dicloridrato de trietilenotetramina $26,78,100$ (Teta), na dose de 1 a $2 \mathrm{~g}$ ao dia.

Nas formas caracterizadas pelo alto grau de rigidez, a associação de L-Dopa pode ser benéfica.

Em casos graves e rebeldes à penicilamina e à trietilenotetramina, o transplante ortotópico de fígado tem proporcionado resultados extremamente favoráveis, com regressāo completa e duradoura das manifestaçôes clínicas e laboratoriais 8,27 . 
Aspecto importante é o relacionado com o momento oportuno para instituir a terapêutica em familiares assintomáticos. A comprovação de defeito bioquímico indiscutivel (ceruloplasminemia inferior a $20 \mathrm{mg} / \mathrm{dl}$; hiperaminoacidúria; concentração de cobre em tecido hepático colhido por biópsia superior a $20 \mathrm{mg} / 100 \mathrm{~g}$, peso seco) impõe a instituição do tratamento, utilizando-se a determinação da cuprurese nos 5 primeiros dias como mais um dado valioso para a confirmação do diagnóstico. Se, porém, o quadro bioquímico não for preciso, fazendo supor que se trate de heterozigoto, deverá o paciente permanecer sob observação, atentando-se especialmente para a funçāo hepática, se se tratar de criança.

Neste particular a experiência de Sternlieb e Scheinberg 84 é convincente: 45 pacientes assintomáticos assim permaneceram durante um período de tratamento de 142 anos-pacientes; uma estimativa baseada na evolução natural da DHL em 121 casos sintomáticos sugere que durante esse intervalo os sintomas deveriam ter aparecido em pelo menos $\mathbf{8}$ daqueles casos. Em 1976 Sternlieb 81 analisou um total de 76 pacientes assintomáticos acompanhados durante um periodo médio de 7 anos, num total de 543 anos-pacientes: em decorrência de irregularidades no tratamento, só 2 desenvolveram sintomas, que regrediram quando a terapêtica passou a ser rigorosamente seguida.

\section{PROGNóSTICO}

O prognóstico quoad vitam depende essencialmente das condiçōes hepáticas por ocasião do diagnóstico e de sua evolução ulterior. Antes de falecer em conseqüência de traumatismo crânio-encefálico, a paciente com maior periodo de seguimento em nossa Clínica, em tratamento com penicilamina, apresentava mínimas manifestaçōes residuais após 15 anos, tendo havido apreciável regressão do anel de Kayser-Fleischer. Os melhores resultados são observados nas formas tardias (tipo pseudosclerose).

\section{RESUMO}

O autor descreve as caracteristicas clinicas e laboratoriais de 102 casos de degeneraçāo hepatolenticular (DHL) acompanhados no Departamento de Neurologia da Faculdade de Medicina da Universidade de São Paulo desde 1946. E analisado o problema do diagnóstico precoce dos familiares, a anatomia patológica da moléstia de Wilson é revista, e săo examinadas as relaçōes entre a DHL e outras moléstias hepatocerebrais. A etiopatogenia é discutida à luz das pesquisas mais recentes, sendo destacado o papel da reduçāo da excreçāo biliar de cobre. A seguir são expostos os resultados do tratamento com D-penicilamina em 84 casos.

\section{SUMMARY}

Hepatolenticular degeneration: a comprehensive review apropos of 102 cases.

The author reports the clinical and laboratory findings in 102 patients of hepatolenticular degeneration (HLD) followed up in the Department of Neurology, University of Sāo Paulo Medical School, since 1946. The problem of the early diagnosis of the relatives is analysed, the pathology of Wilson's disease is reviewed, and the relationship of HLD with other hepatocerebral diseases is examined. Etiopathogenesis is discussed according to current researches, the role of the decreased biliary copper excretion being emphasized. The results of treatment with D-penicillamine in 84 cases are commented. 


\section{REFERENNCIAS}

1. Adams RD, Foley JM - The neurological disorders associated with liver disease. Res Pub Ass nerv ment Dis, 32:198-2'32, 1953.

2. Arioka $I$, Tanimukai $H$, Nishimura $T$, Nishinuma $K$, Ueda $M-$ Histochemical study on hepatolenticular degeneration. Folia psychiat neurol jap., $17: 373-380,1963$.

3. Azevedo EM, Scaff M, Barbosa ER, Gouveia Neto AE, Canelas HM - Heart involvement in hepatolenticular degeneration. Acta neurol scand 58:296-303, 1978.

4. Baker AB - Discussion of the paper by Adams \& Foley. Res Pub Ass Res nerv ment Dis $32: 233-234,1953$.

5. Barka T, Sheuer PJ, Schaffner F, Popver H - Structural changes of liver cells in copper intoxication. Archs Path 78:331-349, 1964.

6. Bearn AG - Genetic and biochemical aspects of Wilson's disease. Am J Med, 15: 442-449, 1953.

7. Bearn AG, Kunkel $\mathrm{HG}_{\mathrm{G}}$ - Abnormalities of copper metabolism in Wilson's disease and their relationship to the aminoaciduria. $J$ clin Invest $33: 400-409,1954$.

8. Beart RW Jr., Putnam CW, Porter KA, Starzl TE - Liver transplantation for' Wilson's disease. Lancet ii:176-177, 1975.

9. Bickel $\mathbf{H}$ - Attempts at caeruloplasmin substituion in Wilson's disease. In Walshe JM \& Cumings JN: Wilson's disease, Some Current Concepts. Blackwell, Oxford, 1961, pp 273-281.

10. Bickel H - Further clinical aspects (Discussion). In Walshe JM \& Cumings JN: Wilson's Disease, Some Current Concepts. Blackwell, Oxford, 1961, p. 249.

11. Van Bogaert L, Willocx E - Êtudes anatomo-cliniques sur la dégénérescence hépatolenticulaire: forme portale de la maladie de Wilson, forme familiale de la pseudosclérose de Westphal-Strümpell. Revue neurol 66:461-497, 1936.

12. Boulding JE - Further clinical aspects (Discussion). In Walshe JM \& Cumings JN: Wilson's Disease, Some Current Concepts. Blackwell, Oxford, 1961, p. 249.

13. Boudin G, Pépin B - Osteoarticular changes in hepatolenticular degeneration. In Walshe JM \& Cumings JN: Wilson's Disease, Some Current Concepts. Blackwell, Oxford, 1961, pp.233-236.

14. Böttiger LE, Möllerborg H - Increased copper content of hypertrophic myocardium. Acta med scand 165:413-416, 1959.

15. Bramwell $B-$ Clinical studies. $\mathrm{X}$ : Familial cirrhosis of the liver: four cases uf acute fatal cirrhosis of the liver in the same family, the patients being respectively nine, ten, fourteen, and fourteen years of age; suggestive relatonship to Wilson's progressive degeneration of the lenticular nucleus. Edinburgh med J 17:90-99, 1916.

16. Cancado ELR, Rocha MS, Barbosa ER, Scaff M, Cerri GG, Magalhães A, Canelas HM - Abdominal ultrasonography in hepatolenticular degeneration: a study of 33 patients. Arq. Neuro-Psiquiat., 45:131-136, 1987.

17. Canelas HM, Carvalho N, Scaff M, Vitule A, Barbosa ER, Azevedo EM - Osteoarthropathy of hepatoienticular degeneration. Acta neurol scand, 57:491, 1978.

18. Canelas HM, de Jorge FB, Tognola WA - Metabolic balances of copper in patients with hepatolenticular degeneration submitted to vegetarian and mixed dicts. J Neurol Neurosurg Psychiat, 30:371-373, 1967.

19. Carrico RJ, Deutsch HF, Beinert H, Orme-Johnson WH - Some vroperties of an apoceruloplasmin-like protein in human serum. J biol Chem, 244:4141-4146, 1969.

20. Cartwright GE, Hodges RE, Gubler CJ, Mahoney JP, Daum K, Wintrobe MM, Bean WB - Studies on copper metabolism. III: Hepatolenticular degeneration. J clin Invest $33: 1.487-1501,1954$.

21. Cole M, Rutherford RB, Smith FO - Experimental ammonia encephalopathy in the primate. Archs Neurol, Chicago, 26:130-136, 1972.

22. Cumings JN - The copper and iron content of brain and liver in the normal and in hepatolenticular degeneration. Brain 71:410-415, 1948.

23. Cumings $I N$ - Trace metals in the brain and in Wilson's disease. $J$ elin Path. 21:1-7, 1968. 
24. Cuming: JN - Biochemistry of basal ganglia. In Vinken PJ \& Bruyn GW: Handbook of Clinical Neurology, Vol. 6 (Disease of Basal Ganglia). NorthHolland, Amsterdam, 1968, pp.116-132.

25. Denny-Brown D - Hepato-lenticular degeneration (Wilson's disease): two different components. New Engl J Med 270:1149-1156, 1964.

26. Dubois RS, Rodgerson DO, Slovis TL, Hambridge KM, Bianchi TA - Triethylentetetramine dihydrochloride in Wilson's disease. Lancet i:775, 1970.

27. Dubois RS, Rodgerson DO, Starzl TE - Copper metabolism in Wilson's discuse: effects of liver transplantation. Resumé des Communications, III ème Syniposium Intermational sur la Maladie de Wilson, Paris, 1973.

\&s. Eastesfield P. - The chemistry of penicillamine. In Walshe JM \& Cumings iN: Wilson'،, Diseuse, Some Current Concepts. Blackwell, Oxford, 1961, pp 254-259.

29. Foller Eli, Shumacher $\mathrm{HR}$ - Ostevarticular changes in Wilson's disease. Arthritis Rheun 15:259-266, 1972.

30. FITZPATRICK TB - Disorders of melanin metabolism. In Wintrobe MM, Thorn GW, Adans RD, Bennett LL, Braunwald E, Esselbacher KJ, Petersdorf R(a: Harrison's l'rinciples of Internal Medicine. McGraw-Hill, New York, ed. 6, 1970, I) 614-620.

31. Fleischer B - Zwei weitere Fälle von grünlicher Verfärbung der Kornea. Klin MbI Augenheilk, 41:489-491, 1903.

32. Fleischer B - Die periphere braun-grünlich Hornhautverfärbung, als symptom einer eigenartigen Allgemeinerkrankung. Münch med Wschr, 96:1120-1123, 1909.

33. Fleischer B - ṫber eine der «Pseudosklerose» nahestehende bisher unbekannte Krankheit (gekennzeichnet durch Tremor, nsychische Störungen, brïunliche Pigmentjerung bestimmter Gewebe, insbesondere auch der IIornhautperipherie, Lebercirrhose). Dt Z NervHeilk, 14:179-201, 1912.

34. Fleming CR, Dickson ER, Wahner HW, Hollen-Horst RW, McCall JT - Pigmented corneal rings in non-wilsonian liver disease. Ann intern Med, 86:285-288, 1977.

35. Frantouls R, Larbre F, Nicolás, Mallein, Rultton-Ugliengo - Maladie de Wilson $\dot{a}$ fornı hépatique pure chęz un nourrison. Lyon méd. 8:467-482, 1958.

36. Franglen GT - Further clinical aspects (Discussion). In Walshe JM \& Cumings JN: Wilson's Disease, Some Current Concepts. Blackwell, Oxford, 1961, p. 248.

37. Frommer D - The measurement of biliary copper secretion in human. Clin Sci, $42: 26 \mathrm{P}, 1972$.

38. Frommer D - The transport of copper in human and rat bile. Resumé des Communications, III eme Symposium International sur la Maladie de Wilson, Paris, 1973.

39. Frommer D, Morris I, Sherlock S, Abrams I, Newman S - Kayser-Fleischer-like rings in patients without Wilson's disease. Gastroenterology, 72:1331-1335, 1977.

40. Goldstein NP, Tauxe WN, McCall JT, Randall RV, Gross JB - Wilson's disease (hepatolenticular degeneration): treatment with penicillamine and changes in hepatic trapping of radioactive copper. Archs Neurol, Chicago, 24:391-400, 1971.

41. Grashchenkov NI, Hekht BM - Copper content of brain tissues in health and in certain nervous diseases. Expl Neurol 2:573-580, 1960.

42. Greenfield $J G$ - Hepatolenticular degeneration (Wilson's disease). In Blackwood W. McMrnemey WH, Meyer A, Norman RM, Russell DS: Greenfieid's Neuropathology. Arnold, London, ed 2, 1965, pp 576-580.

43. Hall HC - La Dégénérescence Hépato-lenticulaire. Masson, Paris, 1921.

44. Haurowitz $\mathrm{F}$ - Über eine Anomalie des Kupferstoffwechsels. Z physiol Chem, $190: 72-74,1930$.

45. Holmberg CG, Laurell $\mathrm{CB}$ - Investigations in serum copper. II: Isolation of the copper containing protein, and a description of some of its properties. Acta chem scand 2:550-556, 1948.

46. Howell JS - Histochemical demonstration of copper in copper fed rats and in hepatolenticular degeneration. J Path Bact 77:473-484, 1959.

47. Kehrer $F-$ Zur Atiologie und Nosologie der Pseudosklerose Westphal-Wilson. $Z$ ges Neurol Psychiat 129:488-542, 1930. 
48. Leu ML, Strickland T, Wang CC, Chen TSN - Skin pigmentation in Wilson's disease. J Am med Ass, 211:1542, 1543, 1970.

49. Lumsden CE - Pathogenetic mechanisms in the leuco-encephalopathles, in anoxicischaemic processes, in disorders of the blood and in intoxications. In Vinken PJ \& Bruyn GW: Handbook of Clinical Neurology, Vol. 9 (Multiple Sclerosis and other Demyelinating Diseases). North-Holland, Amsterdam, 1970, p.638.

50. Lundquist RR - Studies on the pathogenesis of hepatolenticular degeneration. III: The effect of copper on rat liver lysosomes. Am J Path 53:903-927, 1968.

51. Lüthy $F$ - Uber die hepato-lentikuläre degeneration (Wilson-Strümpell). Dt $Z$ NervHeilk, 123:101-181, 1931.

52. Mann T, Keilin D - Haemocuprein and hepatocuprein, copper-protein compounds of blood and liver in mammals. Proc R Soc, Ser B, 126:303-315, 1938.

53. Marecek A, Heyrovsky A, Volek V - The effect of long term treatment with penicillamine on the copper content in the liver in patients with Wilson's disease, Acta hepato-gastroent, 22:292-296, 1975.

54. Martin J P - Wilson's disease. In Vinken PJ \& Bruyn GW: Handbook of Clinical Neurology, vol. 6 (Diseases of the Basal Ganglia). North-Holland, Amsterdam, 1968, pp 267-278.

55. Matsuda I, Holtzman NA - Detection of apoceruloplasmin by radioimmunoassay: preliminary results in copper deficiency, Wilson's disease and Menke's syndrome. Resumé des Communications, III àme Symposium International sur la Maladie de Wilson, Paris, 1973.

56. Mindelzun $\mathrm{K}$, Elkin $\mathrm{M}$, Scheinberg IH, Sternlieb I - Skeletal changes in Wilsun's disease: a radiological study. Radiology, 94:127-132, 1970.

57. Morell AG - Copper and proteins (Discussion). In Walshe JM \& Cumings .IN: Wilson's Disease, Some Current Concepts. Blackwell, Oxford, 1961, p. 52.

58. Morell AG, Irving RA, Sternlieb I, Scheinberg IH - Physical and chemical stuilies on ceruloplasmin. $\mathrm{V}$ : Metabolic studies on sialic acid-free ceruloplasmin in vivo. $\mathrm{J}$ biol Chem, 243:155-159, 1968.

59. Morell AG, Shapiro JR, Scheinberg IH - Copper binding protein from human liver. In Walshe JM \& Cumings JN: Wilson's Disease, Some Current Concepts. Blackwell, Oxford, 1961, pp36-42.

60. Mossakowski MJ, Krasnicka Z, Renhawek K - Contribution des etudes des cellules d'Opalski à la connaissance de la pathogénie des lesions du système nerveux central dans les maladies hépatocérébrales. Revue neurol 125:248, 1971.

61. Opalski A - tuber eine besondere Art von Gliazeelen bei der Wilson-Pseudosklerose-Gruppe. $Z$ ges Neurol Psychiat, 124:420-425, 1930.

62. O'Reilly S, Pollycove M, Tono M, Herradora L - Abnormalities of copper in Wilson's disease. 1I: The internal kinetics of copper. Archs Neurol, Chicago 24:481-488, 1971.

63. O'Reilly S, Strickland T, Weber PM, Beckner WN, Shipley L - Abnormalities of the physiology of copper in Wilson's disease. I: The whole-body turnover of copper. Archs Neurol, Chicago, 24:385-390, 1971.

64. O'Reilly S, Weber PM, Oswald M, Shipley L - Abnormalities of the physiology of copper in Wilson's disease. III: The excretion of copper. Archs Neurol, Chicago, $25: 28-32,1971$.

65. Osborn SB, Walshe JM - Copper uptake by the liver: study of a Wilson's disease family. In Walshe JM \& Cummings JN: Wilson's Disease, Some Current Concepts. Blackwell, Oxford, 1961, pp. 141-150.

66. Osborn SB, Walshe JM - Studies with radiocopper (64Cu) in Wilson's disease: the liver/thigh ratio. Clin Sci, 27:319-328, 1964.

67. Owen CA Jr, Dickson ER, Goldstein N, Baggentoss AH, McCall JT - Hepatic subcellular distribution of copper in primary biliary cirrhosis: comparison with other hyperhepatocupric states and review of the literature. Mayo Clin Proc. $52: 73-80,1977$.

68. Palladini G, Conford A, Medolago L, Venturini G, Zelazek S, Pistone A - Ripro- 
69. Popper $\mathrm{H}-$ Further clinical aspects (Discussion). In Walshe JM \& Cumings JN : Wilson's Disease, Some Current Concepts. Blackwell, Oxford, 1961, p. 249.

70. Rosenoer VM, Michell RC - Skeletal changes in Wilson's disease (hepatolenticular degeneration). Br J Radiol, 32:805-809, 1959.

71. Sass-Kortsal A, Cherniak M, Geiger DW, Slater RJ - Observations on ceruloplasmin in Wilson's disease. $J$ clin Invest, 38:1672-1682, 1969.

72. Scheinberg IH - Coper metabolism: a review. In Walshe JM \& Cumings JN: Wilson's Disease, Some Current Concepts. Blackwell, Oxford, 1961, pp 4-17.

73. Scheinberg IH - Further clinical aspects (Discussion). Walshe JM \& Cumings IN: Wilson's Disease, Some Current Concepts. Blackwell, Oxford, 1961, pp 248-249.

74. Scheinberg $1 \mathrm{H}$ - Discussāo do trabalho de Bickel 9 , pp 282-285.

75. Scheinberg IH, Gitlin D - Deficiency of ceruloplasmin in patients with hepatolenticular degeneration (Wilson's disease). Science, NY, 116:484-485, 1952.

76. Scheinberg IH, Morell AG - Ceruloplasmin. In G. Eichhorn: Inorganic Biochemistry. Elsevier, Amsterdam, 1973, Vol. I, capit. 10, pp.306-319.

77. Scheinberg IH, Sternlieb I - The dual role of the liver in Wilson's disease. Med Clins N Am, 47:815-824, 1963.

78. Scheinberg IH, Sternlieb I - Wilson's Disease. Saunders, Philadelphia, 1984.

79. Scott J, Gollan JL, Samourian S, Sherlock S - Wilson's disease presenting as chronic active hepatitis. Gastroenterology, 74:645-651, 1978.

80. Sternlieb I - Further clinical aspects (Discussion). In Walshe JM \& Cumings JN: Wilson's Disease, Some Current Concepts. Blackwell, Oxford, 1961, p. 248.

81. Sternlieb I - Present status of diagnosis and prophylaxis of asymptomatic patients with Wilson's disease. In $\mathrm{C} M$ Leevy Diseases of the Liver and Billary Tract. Karger, Basel, 1976, pp. 137-142.

82. Sternlieb I, Morell AG, Bauer CD, Combes B, De Bobes-Sternberg S, Scheinberg IH - Detection of the heterozygous carrier of the Wilson's disease gene. $\mathbf{J}$ cltn Invest $40: 707-715,1961$.

83. Sternlieb I, Morell AG, Scheinberg IH - Detection of the heterozygous carrier of the Wilson's disease gene. Resumo in J clin Invest, 38:1046, 1959.

84. Sternlieb I, Scheinberg IH - Prevention of Wilson's disease in asymptomatic patients. New Engl J Med, 278:352-359, 1968.

85. Strümpell A - Über die Westphal'sche Pseudosklerose und über diffuse Hirnsklerose, insbesondere bei Kindern. Dt Z NervHeilk, 12:115-149, 1898.

86. Strlimpell A - Ein weiterer Beitrag zur Kenntniss der sog. Pseudosklerose. Dt Z NervHeilk, 14:348-355, 1899.

87. Summer DW - Further clinical aspects (Discussion). In Walshe JM \& Cumings JN: Wilson's Disease, Some Current Concepts. Blackwell, Oxford, 1961, p. 249.

88. Sunderman FW Jr, White JC, Sunderman FW - Metabolic balance studies in hepatolenticular degeneration treated with diethyldithiocarbamate. Am J Med, $34: 875-888,1963$.

89. Tu J, Blackwell RQ, Hou $T$ - Tissue copper levels in Chinese patients with Wilson's disease. Neurology, Minneapolis, 13:155-159, 1963.

90. Uzman LL: Histochemical localization of copper with rubeanic acid. Lab Invest $5: 299-305,1956$.

91. Uzman LL, Denny-Brown D - Amino-aciduria in hepato-lenticular degeneration (Wilson's disease). Am J med Sci, 215:599-611, 1948.

92. Victor M, Adams RD, Cole $M$ - The acquired (non-Wilsonian) type of chrsnic hepatolenticular degeneration. Medicine, Baltimore, 44:345-396, 1965.

93. Vierling JM, Shrager $R$, Rumble WF, Aamodt $R$, Berman MD, Jones EA Incorporation of radiocopper into ceruloplasmin in normal subjects and in patients with primary biliary cirrhosis and Wilson's disease. Gastroenterology, $74: 652-660,1978$.

94. Voelsch M - Beitrag zur Lehre von der Pseudosklerose (Westphal-Strümpcll). Dt $Z$ NervHeilk, 42:385-352, 1911.

95. Vogel FS, Klemper L - Biochemical reactions of cooper with neural mitochondria, with consideration of the role of the metal in the pathogenesis of Wilson's disease. Laborat Invest 12:171-179, 1963. 
96. Walshe JM - Disturbance of aminoacid metabolism following liver injury: a study by means of paper chromatography. Q Jl Med 22:483-505, 1953.

97. Walshe JM - Wilson's disease: new oral therapy. Lancet i:25-26, 1956.

98. Walshe JM - Penicillamine, a new oral therapy of Wilson's disease. Am J Med, $21: 487-495,1956$.

99. Walshe JM - Management of penicillamine nephropathy in Wilson s disease: a new chelating agent. Lancet, ii:1401-1402, 1969.

100. Walshe JML — Triethylenetetramine. Lancet i:154, 1970.

101. Walshe JM - Wilson's (hepatolenticular degeneration). In Vinken PJ, Bruyn GW \& Klawans HL: Handbook of Clinical Neurology, Vol. 27 (Metabolic and Deficienicy Diseases of the Nervous System), Part I. North-Holland, Amsterdam, 1976, p.379-414

102. Watson DR - Copper metabolism: report of a case of Wilson's disease. J Am osteop Ass, 78:588-596, 1979.

10:3. Westphal C - Über eine dem Bilde der cerebrospinalen grauen Degeneration ihnliche Erkrankung des centralen Nervensystems ohne anatomische Befund, nebst einjgen Bemerkungen über paradoxe Contraction. Arch Psychiat Nervenkr, $14: 87-134,1883$.

104. Wilson SAK - Progressive lenticular degeneration: ‘ familial nervous disease associated with cirrhosis of the liver. Brain, 34:295-507, 1912.

105. Zimdahl WT, Hyman I, Cook ED - Metabolism of copper in hepatolenticular degeneration, Neurology, Minneapolis, 3:569-576, 1953.

Clinica Neurologica, FMUSP - Caixa Postal 3461 - 01000 - Sāo Paulo, SP - Dritsil. 